\title{
Oncological and functional outcomes of salvage renal surgery following failed primary intervention for renal cell carcinoma
}

Fernando G. Abarzua-Cabezas ${ }^{1}$, Einar Sverrisson ${ }^{1}$, Robert De La Cruz ${ }^{1}$, Philippe E. Spiess ${ }^{1}$, Peter Haddock ${ }^{1}$, Wade J. Sexton ${ }^{1}$

${ }^{1}$ H. Lee Moffitt Cancer Center, Tampa, FL 33612, USA

\begin{abstract}
Purpose: To assess the oncologic and functional outcomes of salvage renal surgery following failed primary intervention for RCC.

Materials and Methods: We performed a retrospective review of patients who underwent surgery for suspected RCC during 2004-2012. We identified 839 patients, 13 of whom required salvage renal surgery. Demographic data was collected for all patients. Intraoperative and postoperative data included ischemic duration, blood loss and perioperative complications. Preoperative and postoperative assessments included abdominal CT or magnetic resonance imaging, chest CT and routine laboratory work. Estimated glomerular filtration rate (eGFR) was calculated according to the Modification of Diet in Renal Disease equation.

Results: The majority (85\%) of the patients were male, with an average age of 64 years. Ten patients underwent salvage partial nephrectomy while 3 underwent salvage radical nephrectomy. Cryotherapy was the predominant primary failed treatment modality, with $31 \%$ of patients undergoing primary open surgery. Pre-operatively, three patients were projected to require permanent post-operative dialysis. In the remaining 10 patients, mean pre- and postoperative serum creatinine and eGFR levels were 1.35 $\mathrm{mg} / \mathrm{dL}$ and $53.8 \mathrm{~mL} / \mathrm{min} / 1.73 \mathrm{~m}^{2}$ compared to $1.43 \mathrm{mg} / \mathrm{dL}$ and $46.6 \mathrm{~mL} / \mathrm{min} / 1.73 \mathrm{~m}^{2}$, respectively. Mean warm ischemia time in 10 patients was $17.4 \mathrm{~min}$ and for all patients, the mean blood loss was $647 \mathrm{~mL}$. The predominant pathological stage was pT1a (8/13; $62 \%)$. Negative surgical margins were achieved in all cases. The mean follow-up was 32.9 months (3.5-88 months).

Conclusion: While salvage renal surgery can be challenging, it is feasible and has adequate surgical, functional and oncological outcomes.
\end{abstract}

\section{ARTICLE INFO}

\section{Key words:}

Kidney; General Surgery;

Carcinoma, Renal Cell;

Salvage Therapy

Int Braz J Urol. 2015; 41: 147-54

Submitted for publication:

March 17, 2014

Accepted after revision:

October 10, 2014

\section{INTRODUCTION}

The clinical and financial burden of renal cell carcinoma (RCC) is significant, with its incidence continuing to rise worldwide during the last three decades. In 2011, there were over 60,000 new cases and 13,000 deaths attributed to RCC in the United States alone (1). This rise in diagnosis is likely, at least in part, related to the increased detection of small asymptomatic renal masses using cross sectional abdominal imaging often for unrelated abdominal complaints.

Several treatment options are available for small renal masses (SRMs), including active surveillance, radical nephrectomy, nephron-sparing surgery and ablative procedures. While ablative 
treatment options such as radiofrequency ablation and cryotherapy are commonly used $(1,2)$, there are limited data describing their long-term oncologic outcomes. In comparison, the positive oncologic outcome data for radical or partial nephrectomy are consistent, established and mature $(3,4)$.

Following surgery, cryoablation and radiofrequency ablation, the rate of local recurrences are approximately 3, 5 and $8 \%$, respectively (5, 6). Importantly, the effective management of these recurrences can be challenging, particularly with the use of repeated ablative modalities that tend to have a higher failure rate $(7,8)$. An alternate clinical approach for the treatment of suspected RCC recurrence is salvage partial nephrectomy (SPN). Repeated salvage procedures can achieve adequate functional and oncologic outcomes but are surgically challenging and associated with surgical complications (9-11). Currently limited outcome data are available for salvage renal surgery. As such, in the present study we sought to evaluate the functional and oncologic outcomes following salvage renal surgery at a large, urban, tertiary referral center.

\section{MATERIALS AND METHODS}

Institutional review board approval was obtained for the purposes of this study. We retrospectively reviewed the records of 839 patients who underwent surgery for suspected RCC from 20042012. From this cohort, we identified 13 patients (1.5\%) who underwent salvage renal surgery.

Demographic data was collected for this group of 13 patients. Operative reports and outpatient notes were reviewed for intraoperative and postoperative data, including ischemic duration, blood loss and perioperative complications. Preoperative and postoperative assessments included abdominal CT or magnetic resonance imaging, chest CT and routine laboratory work. Plain films, bone scans, and brain-imaging studies were performed if indicated for accurate preoperative staging. Estimated glomerular filtration rate (eGFR) was calculated (in $\mathrm{mL} /$ $\min / 1.73 \mathrm{~m}^{2}$ ) according to the Modification of Diet in Renal Disease equation:

eGFR $=186($ serum creatinine -1.154$)($ age-0.203)
For female patients eGFR was multiplied by a factor of 0.742, while for African-American patients an adjustment factor of 1.212 was used.

Local recurrence with inferior vena cava tumor thrombus was present in 3 of our patients, and thrombi were classified according to Nieves and Zincke (level I-IV) (12).

\section{RESULTS}

A retrospective review of our institutional kidney cancer database identified 13 patients who underwent salvage renal surgery between 2004-2012. Of these, three of 13 (23\%) required a radical nephrectomy. The majority of the patients $(11 / 13 ; 85 \%)$ were male, with an average age of 64 years (Table-1). Cryotherapy was the main primary treatment modality in six of 13 (46\%) patients, through an open, percutaneous or laparoscopic approach. In contrast, four of 13 (31\%) patients underwent open partial nephrectomy as a primary treatment modality (Table-2).

In the patients included in the study, 11/13 (84.6\%) had clinically diagnosed hypertension. Similarly, 3/13 patients (23.1\%) were diagnosed as diabetic. Three patients (23.1\%) had both hypertension and diabetes (Table-3). The predominance of hypertension and diabetes in our patient cohort is reflected in the profile drugs administered to patients (which included antihypertensives, diuretics, ACE inhibitors, AT1 antagonists, statins and other various agents) (Table-4).

In $12 / 13$ patients (92.3\%), recurrence occurred at the same location as the primary tumor (Table-3). In 11/13 patients (84.6\%) new primary tumors occurred in the same location as the initial tumor (Table-3).

While of interest, proteinuria was not directly assessed in our study cohort. However, in 10 non-dialysis patients, mean pre- and postoperative serum creatinine and eGFR levels were $1.35 \mathrm{mg} / \mathrm{dL}$ and $53.8 \mathrm{~mL} / \mathrm{min} / 1.73 \mathrm{~m}^{2}$ compared to $1.43 \mathrm{mg} / \mathrm{dL}$ and $46.6 \mathrm{~mL} / \mathrm{min} / 1.73 \mathrm{~m}^{2}$, respectively (Table-1). In patients undergoing SPN, mean warm ischemia was $17.4 \mathrm{~min}$. Mean blood loss was $647 \mathrm{~mL}$ for the entire cohort. In 3 of 13 (23\%) patients permanent dialysis after surgery was required, which was related to the fact that 
Table 1 - Summary of patient demographics, clinical data, surgical treatments and pathology.

\begin{tabular}{|c|c|c|}
\hline Mean age (n) & & $64.2(13)$ \\
\hline Gender (M/F) & & $11 / 2$ \\
\hline \multirow[t]{6}{*}{ Primary treatment $(n)$} & Open partial Nx & 4 \\
\hline & Open CA (previous partial nephrectomy) & 1 \\
\hline & Laparoscopic CA & 3 \\
\hline & Percutaneous CA & 2 \\
\hline & Percutaneous RFA & 2 \\
\hline & Hand assisted laparoscopic partial Nx & 1 \\
\hline \multirow[t]{2}{*}{ Serum creatinine $(\mathrm{mg} / \mathrm{mL}) ;($ median; range; $\mathrm{n}=10)$} & Pre-op & $1.4(0.8-2.5)$ \\
\hline & Post-op & $1.4(0.8-2.6)$ \\
\hline \multirow[t]{2}{*}{ eGFR (mL/min/1.73m²); (median; range; $n=10)$} & Pre-op & $53.9(41-60)$ \\
\hline & Post-op & $46.7(15-60)$ \\
\hline \multirow[t]{3}{*}{ Tumor stage (n) } & pT1a & 8 \\
\hline & pT1b & 2 \\
\hline & pT3b & 3 \\
\hline \multirow[t]{2}{*}{ Grade* $^{*}(n)$} & 2 & 2 \\
\hline & 3 & 8 \\
\hline \multirow[t]{4}{*}{ Pathology (n) } & Clear cell & 8 \\
\hline & Papillary & 2 \\
\hline & Oncocytoma & 2 \\
\hline & Fibrosis & 1 \\
\hline Negative margins (n) & & 13 \\
\hline Follow up (months) & & 32.9 \\
\hline Distant recurrence (n) & & 1 \\
\hline
\end{tabular}

*Grading data were unavailable for 3 patients due to their final pathology (2 oncocytomas and 1 fibrosis)

Table 2 - Intra and postoperative complication rates in previously published studies.

\begin{tabular}{lcccc}
\hline & Kowalczyk et al. (18) & Johnson et al. (10) & Bratslavsky et al. (19) & Current study \\
\hline Number of patients & 13 & 47 & 11 & 13 \\
Number of partial nephrectomies & 16 & 51 & 13 & 10 \\
Primary treatment & RFA & Open partial & Open partial & RFA, cryo, \\
open partial \\
Number of intraoperative complications
\end{tabular}


Table 3 - Details of primary treatment, tumor stage, size of relapse, solitary kidney and pathologic stage for individual patients.

\begin{tabular}{|c|c|c|c|c|c|c|c|c|c|}
\hline Patient & $\begin{array}{l}\text { Primary } \\
\text { treatment }\end{array}$ & $\begin{array}{l}\text { Tumor } \\
\text { stage }\end{array}$ & $\begin{array}{l}\text { Tumor size at } \\
\text { relapse }(\mathrm{cm})\end{array}$ & $\begin{array}{l}\text { Primary tumor } \\
\text { location }\end{array}$ & $\begin{array}{l}\text { Location } \\
\text { of relapse }\end{array}$ & $\begin{array}{c}\text { Location of } \\
\text { new primaries }\end{array}$ & $\begin{array}{l}\text { Solitary } \\
\text { kidney }\end{array}$ & $\begin{array}{l}\text { Pathologic } \\
\text { stage }\end{array}$ & $\begin{array}{l}\text { Tumor size } \\
\text { at pathology } \\
(\mathrm{cm})\end{array}$ \\
\hline 1 & $\begin{array}{l}\text { Laparoscopic } \\
\text { cryo }\end{array}$ & cT1a & 3.5 & $\begin{array}{l}\text { Right Posterior } \\
\text { Upper Pole }\end{array}$ & Same & Same & $\begin{array}{c}\text { Solitary } \\
\text { (Anatomical) }\end{array}$ & pT1a NXMX & 3.3 \\
\hline 2 & $\begin{array}{l}\text { Laparoscopic } \\
\text { cryo }\end{array}$ & cT1ab & 4.7 & $\begin{array}{l}\text { Left Anterior } \\
\text { Mid Pole }\end{array}$ & Same & Same & $\begin{array}{c}\text { Solitary } \\
\text { (Anatomical) }\end{array}$ & pT1b NXMX & 4.7 \\
\hline 3 & $\begin{array}{l}\text { Laparoscopic } \\
\text { cryo }\end{array}$ & pT1a & 2.5 & $\begin{array}{l}\text { Left Anterior } \\
\text { Mid Pole }\end{array}$ & Same & Same & $\begin{array}{c}\text { Solitary } \\
\text { (Aantomical) }\end{array}$ & pT1a NXMX & 2.5 \\
\hline 4 & $\begin{array}{c}\text { Renal } \\
\text { cryotherapy }\end{array}$ & cT1b & 6.5 & $\begin{array}{l}\text { Right Medial } \\
\text { Mid Pole }\end{array}$ & Same & Same & Solitary & pT1b NXMX & 6.5 \\
\hline 5 & $\begin{array}{c}\text { Left partial } \\
\text { nephrectomy }\end{array}$ & cT1a & 4 & Left Upper Pole & New & New & Solitary & - & 4.5 \\
\hline 6 & $\begin{array}{l}\text { Right hand } \\
\text { assisted } \\
\text { partial nx }\end{array}$ & pT1a & 4 & $\begin{array}{l}\text { Right Poster } \\
\text { Lower Pole }\end{array}$ & Same & Same & Solitary & pT1aNXMX & 4.0 \\
\hline 7 & 2 open+cryo & pT3bNOMx & 5.5 & $\begin{array}{l}\text { Right Upper } \\
\text { Pole }\end{array}$ & Same & Same & $\begin{array}{c}\text { Solitary } \\
\text { (Functional) }\end{array}$ & PT3c NXMX & 5.0 \\
\hline 8 & RFAx 2 & - & 3.5 & $\begin{array}{c}\text { Left } \\
\text { Posterolateral } \\
\text { Upper Pole }\end{array}$ & Same & Same & $\begin{array}{c}\text { Solitary } \\
\text { (Anatomical) }\end{array}$ & - & 3.5 \\
\hline 9 & $\begin{array}{l}\text { right open } \\
\text { partial }\end{array}$ & pT3bNOMx & 10.5 & $\begin{array}{l}\text { Right Upper } \\
\text { Pole }\end{array}$ & Same & New & $\begin{array}{c}\text { Solitary } \\
\text { (Functional) }\end{array}$ & pT3b NOMX & 10.5 \\
\hline 10 & $\begin{array}{l}\text { Right open } \\
\text { partial }\end{array}$ & pT1aNxMx & 1.9 & $\begin{array}{l}\text { Right Lateral } \\
\text { Upper Pole }\end{array}$ & Same & Same & $\begin{array}{c}\text { Solitary } \\
\text { (anatomical) }\end{array}$ & pT1a NXMX & 1.3 \\
\hline 11 & RFA Left & pT1aNOMx & 1.5 & $\begin{array}{l}\text { Left Anterior } \\
\text { Upper Pole }\end{array}$ & Same & Same & $\begin{array}{c}\text { Multi } \\
\text { (Anatomical) }\end{array}$ & - & 1.3 \\
\hline 12 & Open partial & pT1b & 5.5 & $\begin{array}{l}\text { Right Mid/ } \\
\text { Lower Pole }\end{array}$ & Same & Same & $\begin{array}{c}\text { Solitary } \\
\text { (Anatomical) }\end{array}$ & pT1bNXMX & $6 \times 5.4$ \\
\hline 13 & RFAx2 & pT1aNOMO & 2.5 & $\begin{array}{l}\text { Right mid } \\
\text { pole }\end{array}$ & Same & Same & Solitary & - & 1.6 \\
\hline
\end{tabular}

each had a marginal renal function prior to salvage surgery and IVC tumor thrombus. A single patient had a solitary kidney.

The predominant pathological stage was pT1a $(8 / 13 ; 62 \%)$, while the predominant histology was clear cell carcinoma with a Fuhrman grade 3 (Table-1). Oncocytoma was reported in 2 cases, while only a single patient had no evidence of malignancy in the resected tissue (Table-1). A negative surgical margin was achieved in all cases. In our series, three patients presented with inferior vena cava tumor thrombus, level II and III in 1 and 2 patients, respectively.

The mean follow-up was 32.9 months (3.588 months) and during this period only 1 patient experienced cancer recurrence 6 months following the salvage procedure. The patient underwent a combination of radiation therapy to a lumbar vertebral metastasis and tyrosine receptor kinase therapy. Three of our patients experienced complications 
including prolonged ileus, cecal volvulus and a urinary fistula. All of the patients were treated conservatively consisting of nasogastric tube decompression, endoscopic decompression and double J stent (Figure-1).

\section{DISCUSSION}

Partial nephrectomy is currently considered the gold standard for the effective management of small renal masses (SRMs). In contrast, radical nephrectomy is utilized successfully in clinical scenarios in which partial nephrectomy is either not indicated or not possible from a technical perspective. Despite the benefits of partial nephrectomy and the equivalent oncologic outcomes with radical nephrectomy, it remains underused in the treatment of small renal masses.

Ablative procedures are established modalities for the treatment of SRMs. A number of published studies have described excellent oncologic efficacy with ablative techniques during short and intermediate follow-up periods (5). The majority of published studies describing long term data for oncologic control are relatively small with limited follow-up and lack tumor pathologic diagnosis or are population based-studies that lack substantial details regarding patient comorbidities and demographics. However, intermediate oncological outcomes support the use of this strategy (6).

A growing number of patients opt to undergo ablation as a primary therapy, often because

Table 4 - Patient comorbidities and administered drugs.

\begin{tabular}{|c|c|c|c|}
\hline Patient & Hypertension? & Diabetes? & Drugs administered \\
\hline 1 & Yes & Yes & Aspirin (analgesic), carvedilol (b-blocker), Crestor (statin) \\
\hline 2 & Yes & Yes & $\begin{array}{l}\text { Aspirin (analgesic), Furosemide (diuretic), Glimepiride (sulfonylurea antidiabetic), Lupron (gonadotropin- } \\
\text { releasing hormone antagonist, Metformin (antidiabetic) }\end{array}$ \\
\hline 3 & Yes & No & $\begin{array}{l}\text { Omeprazole (proton pump inhibitor), metoprolol (b-blocker/antihypertensive), Lisinopril (ACE inhibitor), } \\
\text { Fexofenadine (antihistamine), atorvastatin (statin), Amlodipine (Ca channel antagonist - antihypertensive) }\end{array}$ \\
\hline 4 & Yes & No & $\begin{array}{l}\text { Amlodipine (Ca channel antagonist - antihypertensive), Carvedilol (b-blocker), Lisinopril (ACE inhibitor), } \\
\qquad \text { Simvastatin (statin) }\end{array}$ \\
\hline 5 & Yes & No & Atacand/HCT (AT1 inhibitor/diuretic), Spiriva (anticholinergic), Symbicort (COPD) \\
\hline 6 & Yes & Yes & $\begin{array}{l}\text { Allopurinol (xanthine oxidase inhibitor), Amlodipine (Ca channel antagonist - antihypertensive), Bisoprolol } \\
\qquad \text { (b-blocker antihypertensive), Pantoprazole (proton pump inhibitor) }\end{array}$ \\
\hline 7 & Yes & No & Aspirin (analgesic), Lisinopril (ACE inhibitor), Toprol (b-blocker), Simvastatin (statin) \\
\hline 8 & No & No & None \\
\hline 9 & Yes & No & Amlodipine (Ca channel antagonist - antihypertensive) \\
\hline 10 & No & No & $\begin{array}{l}\text { Metoprolol (b-blocker antihypertensive), Hydrochlorothiazide (diuretic), Mirtazapine (antidepressant/ } \\
\text { antiemtic), Fenofibrate (PPARa activator - cholesterol lowering) }\end{array}$ \\
\hline 11 & Yes & No & Cardizem (Ca channel antagonist - antihypertensive), Triamterene (potassium sparing diuretic) \\
\hline 12 & Yes & No & Hydrochlorothiazide (diuretic) \\
\hline 13 & Yes & No & $\begin{array}{l}\text { Lipitor (statin), Plavix (P2PY12 platelet inhibitor), Lotrel (Ca channel inhibitor - antihypertensive), Toprol } \\
\text { (b-blocker), Hydralazine (antihypertensive), Hydrochlorothiazide (diuretic). }\end{array}$ \\
\hline
\end{tabular}


Figure 1 - CT images from a 64 year old patient who failed percutaneous cryotherapy. The patient underwent open salvage partial nephrectomy with no evidence of disease recurrence during 33 months follow-up.
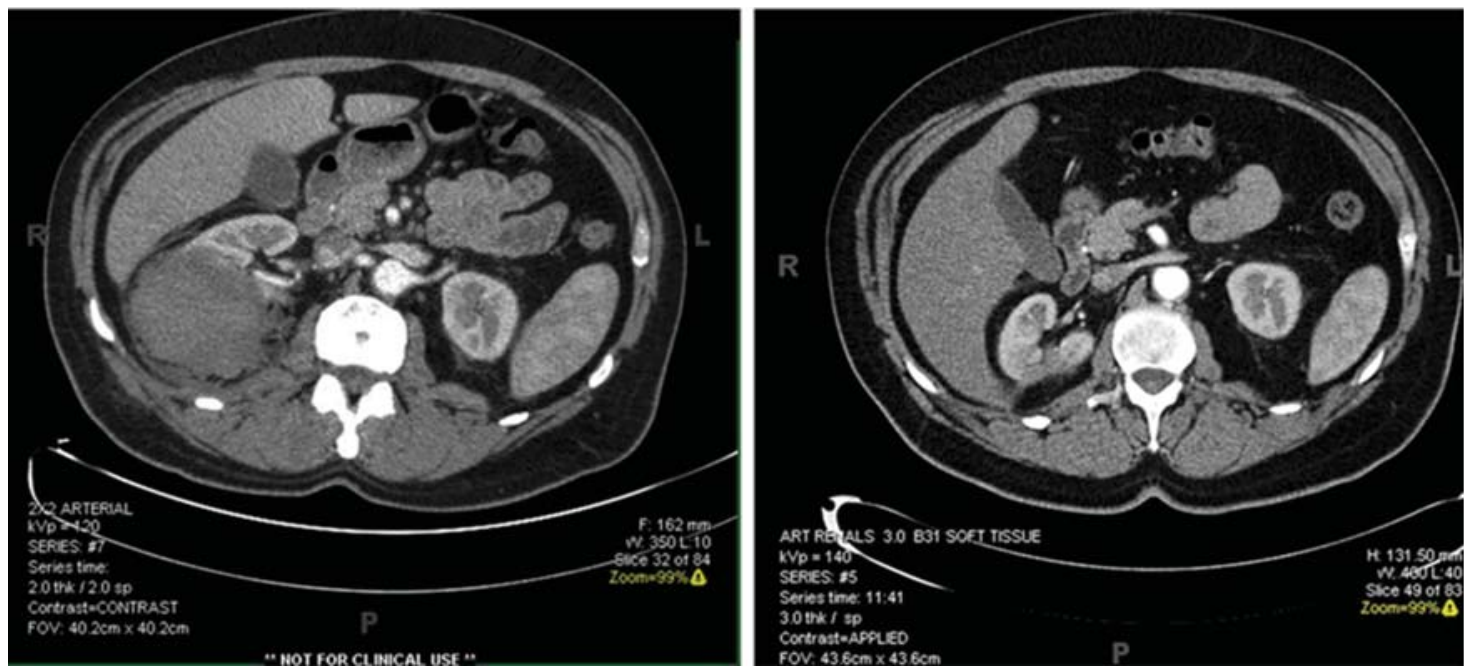

of a solitary kidney, bilateral renal masses or renal insufficiency. However, these patients present challenges should they require subsequent surgery due to disease recurrence or new tumors. A recent large meta-analysis by Kunkle et al. demonstrated an increased risk of local recurrence after cryoablation and RFA compared to partial nephrectomy (13). Many of these cases of recurrence require additional treatments and repeat ablation is used most commonly. However, repeat ablation may not be advisable due to repeated ablation failures, tumor growth after ablation, large tumor size, disease progression, hilar location of a new tumor and proximity of heat sensitive structures. Another possibility may simply include the unwillingness of the patient to undergo the same treatment modality that has failed once already. In these cases, surgical intervention may be required.

There are limited reports describing the feasibility and difficulties of surgery in cases of ablation failure. These surgeries are technically challenging and complicated by severe fibrosis surrounding the previously ablated lesion. Dissections are difficult due to distortion of normal anatomical planes and a high rate of pleural injury (14). Karam et al. recently evaluated the feasibility, safety and pathologic, radiologic and functio- nal outcomes of salvage surgery after prior renal mass ablation therapy (15). They concluded that failed renal ablation therapy can be salvaged with partial or radical nephrectomy with good intermediate outcomes. As a cautionary note, however, they noted that a high rate of adverse events and a requirement for longer follow-up in these patients. As such, patients with multifocal bilateral tumors electing ablative therapy as a primary treatment modality should be aware that new tumors may form in locations not amenable to repeat ablation. In these cases, the challenges involved in salvage surgery are not insignificant.

Barwari et al. (16) recently reviewed the role of different focal treatment modalities in the management of small renal masses. However, there are limited reports of adequate oncological follow-up or standardized assessment of complications (16). The incidence of local recurrence after open surgery or ablative procedures varies depending on the series $(5,8,16)$. In the majority of the cases, post ablation recurrences are treated with a repeat ablation procedure. However, in selected scenarios, surgery is considered to be an efficacious management option. Such cases include rapid tumor growth following primary treatment, or tumors in unfavorable locations such as the collecting system or the renal hilum. 
Recently published data have described the long-term impact on cardiac and renal function in patients who underwent radical nephrectomy rather than nephron sparing procedures $(8,9$, 16). Kaushik et al. (17) demonstrated a four-fold increase in the risk of developing stage IV CKD following radical nephrectomy in a univariate and multivariable analysis compared with partial nephrectomy following surgery for a benign renal mass (17). In a major clinical study, Johnson demonstrated an adequate functional outcome with minimal decline in serum creatine and creatinine clearance following partial nephrectomy (10). Furthermore, Weight et al. (11) demonstrated an increased incidence of cardiovascular and renal complications, including chronic kidney disease and a requirement for postoperative dialysis, in patients who underwent radical nephrectomy as compared with nephron sparing surgery (NSS) (11). The health care impact of repeated NSS may be greater compared to undertaking an initial partial nephrectomy, due to the inherent complications of reoperative surgery and associated prolonged hospital stay. However, hemodialysis and its associated complications cost approximately $\$ 70,000$ per year, per patient. As such, reoperative NSS (which is significantly less costly), may be a more cost effective option compared to dialysis (18).

Salvage surgery can be technically challenging and is often associated with significantly higher complication rates when compared with procedures performed in a virgin surgical field. In particular, an increased incidence of injury to adjacent organs such as the bowel, spleen, pancreas, liver and diaphragm, has been described $(10,11)$. Analyses of recurrent disease following thermal ablation have demonstrated that cryoablation is often associated with a significant degree and incidence of fibrosis and adhesive scarring around the kidney as compared to radiofrequency ablation, in which this side effect tends to be less extensive (19).

Two of our patients had multiple procedures before the salvage procedure including repeated open procedures and cryotherapy treatment. However, it did not preclude an increased number of complications.

In our series, three patients experienced significant local progression of their tumors with
IVC involvement and subsequently underwent radical nephrectomy and IVC thrombectomy. Two of the patients had failed initial open renal cryoablation and the remaining patient failed an initial complex partial nephrectomy. The finding of such significant disease progression illustrates how important it is for surgeons managing renal tumors to select appropriate therapeutic strategies based on the characteristics of the primary tumor.

Three post-operative complications were managed conservatively. However, no major intraoperative complications or injuries to any adjacent organs were reported. In contrast, in other published studies intraoperative and postoperative complications occurred in approximately 44\% of cases (Table-2). Six of our patients received cryoablation delivered by different approaches. An increased complication rate in patients previously treated with cryotherapy has been described previously. However, in our study group the intraoperative complications were significantly less frequent.

Following the salvage renal surgery pathology revealed nonmalignant tumors or findings including oncocytoma in two patients and fibrosis in 1 patient. Park and Weight $(11,20)$ investigated the role of the imaging studies and biopsies in patients who underwent RFA or cryoablation. The authors concluded that for cryoablation, contrast enhancement was a reliable tool and follow-up biopsies were of low value whereas after RF ablation, radiologic findings were not reliable and follow-up biopsies had an impact on further decision making $(11,14)$. In our series, none of our patients underwent a confirmatory biopsy before the salvage procedure. Surgical decisions were based on supporting imaging studies.

Limitations of the current study include the retrospective nature of this report, the small number of patients included for review, the lack of pre-operative confirmatory biopsies prior to salvage renal surgery, and of course the inherent selection bias of patients chosen for salvage renal surgery. We did not include an evaluation of patients who were refused salvage surgery or who elected observation for a suspected recurrence of their tumors. However, our findings are comparable to other small series that share similar limitations. 


\section{CONCLUSIONS}

Data from this study illustrates that while a re-operation can be challenging, it is both feasible and associated with adequate surgical, functional and oncologic outcomes. While the technically challenging nature of salvage renal procedures following a primary treatment can be associated with an increased frequency of complications, this is not associated with significant renal dysfunction or adverse oncologic outcomes.

\section{ABBREVIATIONS}

$\mathrm{SRM}=$ Small renal mass

SPN = Salvage partial nephrectomy

RCC $=$ Renal cell carcinoma

eGFR = Estimated glomerular filtration rate

$\mathrm{EBL}=$ Estimated blood loss

NSS $=$ Nephron sparing surgery

\section{CONFLICT OF INTEREST}

None declared.

\section{REFERENCES}

1. Singer EA, Gupta GN, Srinivasan R. Targeted therapeutic strategies for the management of renal cell carcinoma. Curr Opin Oncol. 2012;24:284-90.

2. Weld KJ, Landman J. Comparison of cryoablation, radiofrequency ablation and high-intensity focused ultrasound for treating small renal tumours. BJU Int. 2005;96:1224-9.

3. El Dib R, Touma NJ, Kapoor A. Cryoablation vs radiofrequency ablation for the treatment of renal cell carcinoma: a meta-analysis of case series studies. BJU Int. 2012;110:510-6.

4. Shuch B, Linehan WM, Bratslavsky G. Repeat partial nephrectomy: surgical, functional and oncological outcomes. Curr Opin Urol. 2011;21:368-75.

5. Campbell SC, Novick AC, Belldegrun A, Blute ML, Chow GK, Derweesh $\mathrm{IH}$, et al. Practice Guidelines Committee of the American Urological Association. Guideline for management of the clinical T1 renal mass. J Urol. 2009;182:1271-9.

6. Goel RK, Kaouk JH. Probe ablative treatment for small renal masses: cryoablation vs. radio frequency ablation. Curr Opin Urol. 2008;18:467-73.

7. Nguyen CT, Lane BR, Kaouk JH, Hegarty N, Gill IS, Novick AC, et al. Surgical salvage of renal cell carcinoma recurrence after thermal ablative therapy. J Urol. 2008;180:104-9; discussion 109.
8. Breda A, Anterasian C, Belldegrun A. Management and outcomes of tumor recurrence after focal ablation renal therapy. J Endourol. 2010;24:749-52.

9. Russo P. Oncological outcomes of partial nephrectomy for renal carcinoma greater than $4 \mathrm{~cm}$. Curr Opin Urol. 2011;21:362-7.

10. Johnson A, Sudarshan S, Liu J, Linehan WM, Pinto PA, Bratslavsky G. Feasibility and outcomes of repeat partial nephrectomy. J Urol. 2008;180:89-93; discussion 93.

11. Weight CJ, Larson BT, Fergany AF, Gao T, Lane BR, Campbell SC, et al. Nephrectomy induced chronic renal insufficiency is associated with increased risk of cardiovascular death and death from any cause in patients with localized cT1b renal masses. J Urol. 2010;183:1317-23.

12. Neves RJ, Zincke H. Surgical treatment of renal cancer with vena cava extension. Br J Urol. 1987;59:390-5.

13. Kunkle DA, Uzzo RG. Cryoablation or radiofrequency ablation of the small renal mass: a meta-analysis. Cancer. 2008;113:2671-80.

14. Kowalczyk KJ, Hooper HB, Linehan WM, Pinto PA, Wood BJ, Bratslavsky G. Partial nephrectomy after previous radio frequency ablation: the National Câncer Institute experience. J Urol. 2009;182:2158-63.

15. Karam JA, Wood CG, Compton ZR, Rao P, Vikram R, Ahrar K, et al. Salvage surgery after energy ablation for renal masses. BJU Int. 2015;115:74-80.

16. Barwari $\mathrm{K}$, de la Rosette JJMCH, Laguna MP. Focal therapy in renal cell carcinoma: which modality is best? Eur Urol. 2011; 10(Suppl):e52-57.

17. Kaushik D, Kim SP, Childs MA, Lohse CM, Costello BA, Cheville $\mathrm{JC}$, et al. Overall survival and development of stage IV chronic kidney disease in patients undergoing partial and radical nephrectomy for benign renal tumors. Eur Urol. 2013;64:600-6.

18. Liu NW, Khurana K, Sudarshan S, Pinto PA, Linehan WM, Bratslavsky G. Repeat partial nephrectomy on the solitary kidney: surgical, functional and oncological outcomes. J Urol. 2010;183:1719-24.

19. United States Renal Data System. Excerpts from USRDS 2009 Annual Data Report. U.S. Department of Health and Human Services. The National Institutes of Health, National Institute of Diabetes and Digestive and Kidney Diseases. Am J Kidney Dis. 2010;55(Suppl 1):S1

20. Park S, Strup SE, Saboorian H, Cadeddu JA. No evidence of disease after radiofrequency ablation in delayed nephrectomy specimens. Urology. 2006;68:964-7.

Correspondence address: Fernando G. Abarzua-Cabezas, MD Urology Division Hartford Healthcare Medical Group 85 Seymour Street, Suite 416 Hartford, CT 06106 Fax: 860-524-8643 E-mail: fernando.abarzua-cabezas@hhchealth.org 